\title{
Mapping Uncertainties in the Upstream: The Case of PLGA Nanoparticles in Salmon Vaccines
}

\author{
Kåre Nolde Nielsen • Børge Nilsen Fredriksen • \\ Anne Ingeborg Myhr
}

Received: 16 December 2010 / Accepted: 26 February 2011 /Published online: 29 March 2011

(C) The Author(s) 2011. This article is published with open access at Springerlink.com

\begin{abstract}
The diversity of nanotechnologies and of the governance challenges that their applications raise calls for exploration and learning across different cases. We present an Upstream Oversight Assessment (UOA) of expected benefits and potential harms of nanoparticles made of a synthetic polymer (PLGA) to improve vaccines for farmed salmon. Suggested by Jennifer Kuzma and colleagues, an UOA may help identify and prioritise research needs, and it may support evaluations of the adequacy of relevant existing regulatory frameworks. In this work, the UOA approach is modified and supported with elements from the uncertainty analysis framework developed by Warren Walker and colleagues. Empirically, we draw on relevant available published literature and insights generated in an ongoing nanoparticle salmon vaccine project, in which one of the authors participates. Nanotechnologies have not pre-
\end{abstract}

K. N. Nielsen $(\bowtie) \cdot$ A. I. Myhr

GenØk-Centre for Biosafety,

Forskningsparken, Breivika 9294 Tromsø, Norway

e-mail: kare.nolde.nielsen@genok.no

A. I. Myhr

e-mail: anne.myhr@genok.no

B. N. Fredriksen

Norwegian College of Fishery Science,

Faculty of Biosciences, Fisheries and Economics,

University of Tromsø,

9037 Tromsø, Norway

e-mail: bfr000@nfh.uit.no viously been encountered in the regulatory context of fish vaccines, which in part raises unique challenges due to prospective large scale vaccine use in semiopen aquatic systems. Strengthened through cooperation between ELSA and technology researchers we found the UOA useful for an early mapping of benefits and concerns, and for identifying areas in need of further research prior to a nanoparticle based salmon vaccine is developed and taken into use. We consider our approach to represent one among several complementing initiatives that seek to contribute to early stage evaluations of possible negative side effects, broadly conceived, in order to facilitate a more robust nanotechnology development.

Keywords Nanotechnology PLGA $\cdot$ Upstream oversight assessment $\cdot$ Vaccines $\cdot$ Salmon .

Uncertainty $\cdot$ Risk $\cdot$ Anticipatory governance

\section{Facilitating Anticipatory Governance of Nanotechnologies}

A primary scientific rationale for delineating nano as a new field is that objects can express novel properties at the nanoscale. Although the limits of the nanoscale remain disputed, the weight given to this scale in definitions of 'nanoscience' and 'nanotechnology' allows the latter terms to refer to a highly diverse range of disciplines, activities and objects. Discussions about risk governance of nanotechnologies 
include examples such as carbon nanotubes, nanoparticles made of different metal oxides and nanosilver. If these examples are prominent in risk oriented nanotechnology discourses, it is not without reason. The mentioned examples are important because they are either already used on a rather large scale in a range of products or are expected to be so in the near future. Further, toxic effects have been identified for such nanomaterials in different animal model systems, and/or they have been found to involve environmental hazards.

Nanotechnology has been taken to offer an arena for experimenting with ways to include societal, ethical and environmental concerns in early stages of innovation processes in order to promote a more robust technology development [52]. This includes efforts to foresee social and environmental implications of emerging technologies, to engage wider publics in innovation processes, and to enhance the sensitivity and reflexivity of technology developers to social and environmental concerns. These efforts may be collected under the broad term 'anticipatory governance' [7, 37]. The scope of this work, however, is more limited, as we here focus on addressing benefits, harms and uncertainties of a specific nanotechnology application.

Emphasising the diversity of nanomaterials and the diversity of the particular challenges that may associate their use in different contexts, we explore prospects and concerns of a project in immunobioengineering that investigates the potential of polymeric micro- and nanoparticles to enhance vaccine formulations for farmed salmon. Drawing on previous experiences with the use of polymer PLGAs (polylactide-co-glycolic acids) in targeted drug delivery in other contexts, the objective of this research is to develop efficacious vaccines against intracellular pathogens, which are not easily addressed by way of standard vaccines. A successful vaccine of this kind would have significant positive influence on animal welfare and the economics of salmon farming. This is an application of nanotechnology that to our knowledge has not been addressed earlier in nanotechnology governance discourses.

We examine this case by way of a modified Upstream Oversight Assessment (UOA). Developed by Kuzma [43, 44], the aim of this approach is to contribute to a robust technology development through identifying knowledge gaps, through indicat- ing priorities for further research, and through considerations of the adequacy of relevant existing regulatory frameworks. The UOA may in this way contribute to that public trust in technologies is fostered. Although we note that a comprehensive evaluation of salmon vaccines ultimately should also take broader questions of the ethical and environmental sustainability of salmon farming (in its present form) into account [63], we consider these broader issues to be outside the scope of this article.

While the PLGA material is considered to be rather low toxic in itself, the prospect of using it in nanoparticle vaccines in context of aquaculture raises a range of unique concerns, for instance relating to that the vaccine is to be used in a rather different animal (i.e. fish vs. mammals), and to the use of large volumes of vaccine particles in semi-open marine systems (i.e. salmon farms). We find that the approach taken may help identify issues in need of further research and regulatory attention prior to a finalization and marketing of such nanoparticle based fish vaccines. As relevant to this case, we offer concrete suggestions for doing so.

In general, however, we find it unlikely that there will be resources available for performing an upstream assessment of this kind for each nanotechnology research project. Accordingly, we end this article by endorsing the further development of voluntary measures and codes of conducts for good technology research practise. Along with the approach taken here, these initiatives may stimulate a more robust nanotechnology research development in different contexts.

\section{Methodology, Concepts and Materials}

We explore the case PLGA nanovaccines for salmon by way of a modified Upstream Oversight Assessment (UOA). Developed and proposed by Kuzma $[43,44]$ the UOA is a case based method, the purpose of which is to draw attention to areas in need of further research in order to help prepare for the governance of these technologies. It focuses on potential implications of emerging nanotechnologies including benefits and issues of hazard and exposure for researchers, workers, consumers and the environment. It does so through addressing beneficial properties as well as safety issues of nanomaterials in the context of their application, and through 
identification of strengths and weaknesses of relevant regulatory and monitoring frameworks.

In practise, the UOA proceeds from posing a series of research questions, which are answered to the extent possible through available means. This work has been guided by the following questions, which we have adapted from Kuzma et al. [44] with respect to the present case: What are expected benefits of using PLGA nanoparticles in salmon vaccines? What are the identified risks, and what are the uncertainties with regard to harmful impacts on human health and the environment? What information would be needed to further address risks, uncertainties and benefits? Which regulatory frameworks are involved, and are there particular regulatory uncertainties in this context?

For the purpose of this work, we have modified the UOA in two significant ways. First, the UOA as suggested by Kuzma and colleagues is a comparative method, which proceeds to develop a relative ranking of the pertinence of relevant issues in need of further attention across a range of nanotechnology applications within a certain area. As our work comprises only one case study, it does not feature a comparative aspect. The choice of working with only one case, however, allows for a more comprehensive analysis. What we gain in the 'assessment' dimension of the UOA we forgo with respect to 'oversight'.

Second, we have supported the UOA approach with elements from the uncertainty analysis framework developed by Walker et al. [74]. This framework has previously been used for analyzing uncertainties of other emerging technology applications, including GMO crops [41], gene-silencing [42], and DNA vaccines in salmon aquaculture [27]. The framework has also been used to review the state of knowledge and uncertainty of environmental health and safety aspects of nanomaterials in general [29]. In accordance with this framework, we use 'uncertainty' as a generic term for the situation of imperfect knowledge. In this framework, uncertainty is seen to include three dimensions. First, 'location' identifies where the uncertainty is manifested within a system model. Second, 'level' identifies the degree of uncertainty, spanning from 'statistical uncertainty' over 'scenario uncertainty' and 'recognized ignorance' to 'complete ignorance'. Third, 'nature' concerns the issue of whether uncertainty may be epistemic (and hence be reducible) or ontic (due to variability).
Along with Walker et al. [74], we structure our analysis of uncertainties in terms of their location. However, while 'location' for Walker and colleagues is determined in relation to a (qualitative or quantitative) cause-effect model, this is not the case here. In this work, location refers to a (conceptual) map of the system in which it is plausible that the nanotechnology in question may have significant impacts for humans and the environment. Further, the question of uncertainty levels will only be responded to in terms of rather generalized characterizations. As the term 'risk' is commonly conceptualized quantitatively as the product of the magnitude of hazard and the likelihood of exposure, it is here understood as 'statistical' uncertainty. We note that as no such relationships have been quantified for the vaccine examined here, the term risk does not apply. Accordingly, addressed uncertainties in this case range between 'scenario uncertainty' and 'recognized ignorance'.

Empirically, we primarily draw on the available published literature relevant to PLGA, its use in nanoparticles, fish vaccinology, and existing fish vaccine regulations with relevance to the European Economic Area (EEA) and Norway in particular. Further, we benefit from insights generated in an ongoing project that seeks to develop PLGA nanoparticle based salmon vaccines, in which one of the authors (B.N. Fredriksen) participates.

\section{The Case of PLGA Nanoparticles for Salmon Vaccines}

Polymers have been used in pharmaceutical applications for several decades. One of the most common methods for microencapsulation dates back to the late 1980s [62], and is still in use today although with modified protocols. The following section aims at introducing the relevance of PLGA polymers for fish vaccines.

\section{A Need for Efficient Fish Vaccines}

Following a shift from farming in ponds to the use of sea pens in the 1970s, salmon aquaculture has expanded tremendously. In Norway, salmon aquaculture production has grown from less than $50.000 \mathrm{t}$ in 1987 to a level of close to $1.000 .000 \mathrm{t}$ in 2010 , maintaining Norway as the leading exporter of farmed 
salmon worldwide. A key factor to the continuous growth of the salmon farming industry has been the development of effective fish vaccines [11, 70]. During the late 1980s and early 1990s the use of antibiotics reached its peak due to massive outbreaks of bacterial diseases. Introducing oil-adjuvanted vaccines (adjuvants are agents that modify/enhance effects of other agents) with inactivated bacteria as antigens drastically reduced the number of outbreaks and the losses from these diseases became negligible [20, 22, 54].

In spite of their importance for modern salmon aquaculture, available oil-based vaccines only provide sub-optimal protection towards some pathogens, notably a range of viruses, intracellular bacteria and macro-parasites [33, 70]. An important example is the salmon vaccines against a highly infectious viral disease, infectious pancreatic necrosis virus (IPN), for which there still are no commercial vaccines available that confer long lasting immunity [30]. In 2009 there were 223 outbreaks of IPN in Norway [59]. Moreover, the traditional oil-adjuvanted vaccines have been found to have side effects such as injection site organ adhesions, melanin deposition and skeletal deformations [11]. Further, incidents have been reported on systemic autoimmunity in farmed salmon [39]. While vaccine derived side effects have been reduced through optimization of existing adjuvant formulations, a strong motivation remains for developing new vaccine formulations to help reduce the spread of viral diseases.

\section{The Role of Carrier Systems in Vaccinology}

In later years there has been a general trend within vaccine research to design delivery systems that are able to mimic pathogens in size and composition. Examples include virosomes, liposomes and polymeric nanoparticles. Such structures may be loaded with specific drugs of which they facilitate delivery to intracellular compartments through pathways involved in natural infections in order to obtain desired and optimal immune responses against a given pathogen. Although the field of immunology is outside the scope of this text, a brief introduction is needed to get a better understanding of the potential these carrier systems have in vaccine antigen delivery.

After vaccination, or during natural infections, antigen presenting cells (APCs) play a central and orchestrating role for generation of adaptive immune responses in mammals [6]. APCs include dendritic cells (DCs), B-lymphocytes (B-cells) and macrophages, and their main role is to initiate an immune response by alerting other cells about pathogens entering the body. In fish, macrophages are considered to be the target orchestrator of adaptive immunity. DC-like cells have only recently been identified [51], and the role of B-cells as APCs is preliminary described [49]. Macrophages have the ability to phagocytose (engulf and digest) pathogens and present the foreign antigens on the cell surface to prime other cells to recognize the same structures.

Depending on the agonist (adjuvant/antigen), activation of macrophages initiates the humoral (antibody production) and/or the cellular (cytotoxic T cells) arm of the immune response. These two arms are effector mechanisms against extra- and intracellular pathogens, respectively.

Most vaccines elicit a humoral response resulting in antibody production. As they seem to fail to activate the cellular immune repertoire they provide poor protection against intracellular pathogens. The latter represents a key challenge in antiviral vaccine design [77]. Cellular responses can generally not be induced by non-living vaccines [53]. While potentially effective, not least within veterinary vaccines [18], the use of attenuated virus strains includes the risk of virus reverting into virulent forms (e.g. [67]). However, the APCs have the ability to initiate the cellular arm in response to inactivated antigens, a property called crosspresentation. Vaccine researchers can exploit this property by designing vaccines that mimic intracellular pathogens.

Immunobioengineering Using Small Polymeric Particles

The use of polymeric micro- and nanoparticles in vaccine delivery systems represents a novel approach in the context of aquaculture. Aiming at modulating immune responses in specific and desired ways, this approach may be called 'immunobioengineering' as it combines knowledge in material sciences with immunology [35]. Increased vaccine efficacy and reduced severity of side effects may be achieved by targeting specific immune cells and their intracellular (signalling) pathways $[17,55]$. A broad range of low-toxic 
and biodegradable materials can be used to make micro and nano sized vaccine antigen carriers, with PLGAs (poly lactide-co-glycolic acids) being among the most extensively explored polymers for targeted drug delivery. Due to their different physical and chemical properties one can modulate co-polymer composition (e.g. lactic:glycolic ratio, surface charge and molecular weight) and particle size in order to alter particle-cell interactions, degradation kinetics and antigen release. Control of the rate of cellular uptake and antigen release profiles can be utilized to design vaccines with prolonged and/or pulsative antigen availability and/or presentation in intra- and extracellular compartments. The control of degradation profiles may also enable development of other vaccine delivery systems for fish, two highly relevant examples being oral or intramuscular (plasmid DNA) vaccines.

Expected Benefits of PLGA Particles in Fish Vaccine Formulations

The overall objective of developing a novel particle based vaccine concept for fish is the same as for the development of any other vaccines: to prevent outbreak and spread of diseases. There are currently no treatments for viral diseases in aquaculture. Given the prophylactic approach taken by the Norwegian aquaculture industry, vaccination therefore represents a key strategy to combat diseases. Reduced incidences of disease outbreaks and reduced adverse side effects have positive implications for fish welfare as well as cost-efficiency in the industry. For some diseases, like the earlier mentioned IPN, the mortality during an outbreak can be as high as $90 \%$ at one farm site. The economic setback of such serious outbreaks can exceed a million USD, not least when reduced fish growth and product quality is taken into account. The pertinence of the issue of fish welfare is emphasized by the recent law on animal welfare in Norway, which entered into force at the beginning of 2010 [60]. In addition, spread of diseases between farmed and wild fish is possible as they live in the same environment, indicating that efficient vaccines may also contribute to the preservation of a healthy and viable wild life.

On a technical level, the PLGA particle delivery system comes with a range of advantages. First, the particles serve to protect against premature drug degradation, and they enable spatio-temporal control of drug release. This makes it possible to prepare vaccines with controlled biodistribution, depot (antigen availability over time), cellular targeting and intracellular routing [46]. Second, the particles are in the same size range as bacteria and viruses, and they are therefore readily taken up by APCs [68]. It has been shown that cross-presentation may be enhanced when antigens are attached to (sub-) micron sized particles as compared to the use of soluble antigens (e.g. [40]). Third, PLGA particles can also be loaded with 'danger signals' in order to elicit stronger responses directed to stimulate the cellular arm of the immune system [16, 21, 69]. By co-encapsulating antigens and danger signals the two components are able to effectuate their actions simultaneously, thereby mimicking pathogens in size and composition. It has been shown that co-encapsulation of antigens and danger signals in PLGA particles induces a strong antibody response as well as a cellular response [69].

In a broader perspective, PLGA vaccines formulations may render use of live or plasmid DNA vaccines redundant. This could be the case if the PLGA vaccines have higher efficacy towards intracellular pathogens than conventional oil-adjuvanted vaccines. If use of DNA and genetically modified vaccines is avoided, this would eliminate biosafety risks associated with the use of such vaccine concepts [24].

In sum, incentives to search for new and improved vaccine concepts are evident from multiple perspectives, including those of animal welfare, fish farmers and the sustainability of wild fish populations. The strategy of using PLGA nanoparticles in vaccine delivery comes with a number of technical advantages, which, however, remains to be demonstrated in the context of salmon vaccines.

\section{Uncertainties Regarding Harmful Effects of PLGA Based Salmon Vaccines}

The goal of using nanocarriers in drug delivery is to achieve optimal prophylactic or therapeutic effects while minimizing drug hazards. Nevertheless, it has been questioned whether the safety of drug carriers themselves have been appropriately scrutinized [36]. Another aspect of nanomedicines that generally has been devoted scarce attention is their possible 
negative environmental effects [8]. In this section, we will systematically explore uncertainties regarding harmful effects of PLGA based salmon vaccines.

\section{Mapping Locations of Salmon PLGA Vaccines}

While the vaccinated animal constitutes the focal point for uncertainties relating to the vaccine, the production and use of the vaccine may have unintended effects at other locations (Fig. 1 below). To begin with, it is relevant to know where the vaccine material enters the body of the salmon. It can be absorbed through the gut (edible vaccines), over the gills (immersion vaccines), or it can be deposited in muscle tissue or the abdominal cavity (injected vaccines), the latter being most relevant for the PLGA formulations addressed here. Further, it is relevant to know the biodistribution and pharmacokinetics/ dynamics of the particles post injection. However, the vaccine material may also be excreted or leak from the individual. The salmon itself may escape from the salmon farm facility and into the surrounding aquatic environment. Vaccine materials may also enter the aquatic environment by way of vaccine spills or through decomposition of vaccine containing salmon tissue (e.g. offal and dead fish).

In addition, vaccine residues may end up in the salmon muscle tissue and may be consumed by humans or animals (e.g. escaped salmon in the wild). Finally, humans may physically come in contact with the vaccine through research, production and administration. The following presentation of uncertainties regarding this fish vaccine will generally move from left towards right in Fig. 1. We revisit each of these locations to present available knowledge and to identify knowledge gaps. We start with a presentation of the PLGA material and its application in delivery of therapeutics, notably micro- and nanoparticle vaccines. Then we proceed to concrete matters of salmon vaccines in the fish and beyond. Reflecting the availability of knowledge along this trajectory, our presentation will become decreasingly anchored in existing research and accordingly become increasingly suggestive.

\section{PLGA and its Use in Delivery of Therapeutics}

Nanomedicines, including nanoparticle based vaccines, mainly involve two components; a drug and a carrier system [36]. We begin with some general experiences with its use in medical applications before we turn to its use in small particles for drug delivery.

PLGA has been approved by the US food and drug administration (FDA) for a range of medical clinical applications [50]. PLGA has for instance been used in surgical sutures [26] and in bone fracture fixation in humans and other mammals. Concerning their safety

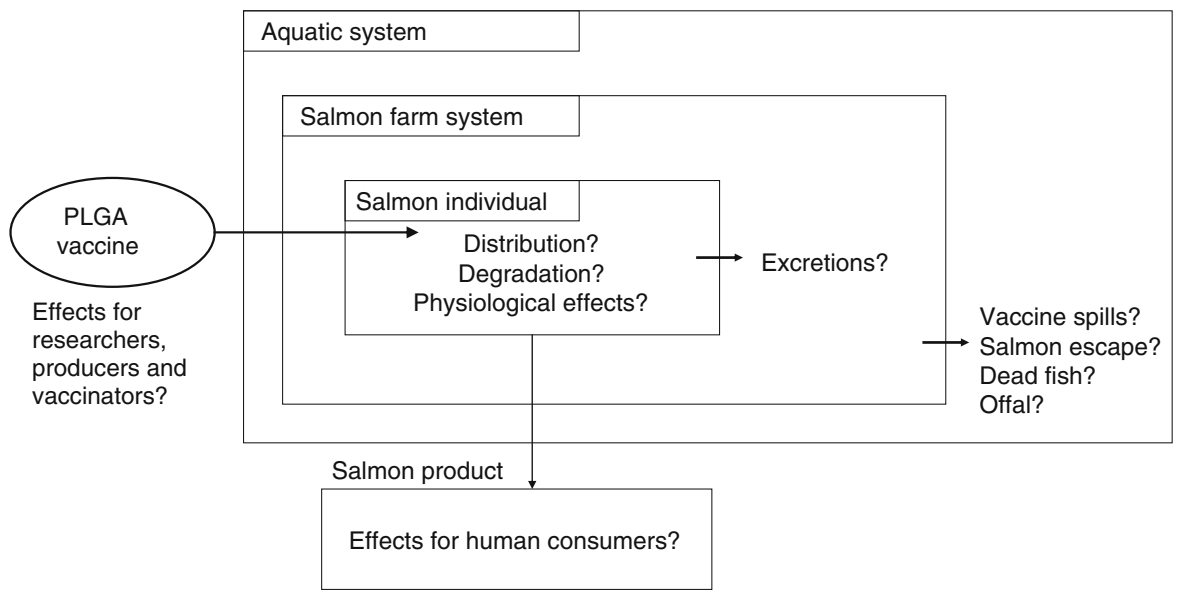

Fig. 1 Conceptual map locating conceivable uncertainties of salmon vaccines in relation to a nested system of potential containment or leakage. Once administrated, vaccines may be contained within (or leaked from) an individual salmon. In turn, the salmon may be contained within the salmon farm system or may escape into the external aquatic environment. Slaughtered salmon, which may contain vaccine, enters into a (terrestrial) production chain, making it available for human consumption. Professionals may come in contact with the vaccine through research, production and administration of the vaccine (see text for discussion) 
in medical application and otherwise, PLGAs have two general advantageous properties: Biocompatibility and biodegradation, properties often stated as part of what motivates new applications.

The PLGA molecule degrades in an aqueous environment, whether in vitro or in vivo, because the ester bonds that form the backbone of the polymer will hydrolyze, releasing the lactic acid and glycolic acid of which it is constituted. These acids are eventually metabolized though the citric acid cycle or excreted [4]. The rate of degradation depends on a range of factors such as co-polymer composition (i.e. the ratio of lactic to glycolic acid), site of administration, additives (including drugs in delivery systems), size, surface charge and shape of the device or particle, and its porosity and $\mathrm{pH}[5,9,23,32,65$, 76, 78].

The biocompatibility of PLGA has been reviewed previously [2, 4]. In macroscopic applications, PLGA has been found to be biocompatible over longer time horizons (e.g. several months to more than a year) and the documented side effects of PLGA appear limited to that its degradation may cause acidic conditions locally [4]. Small PLGA particles, however, have been found to elicit inflammatory processes. It has been suggested that the chemical- (co-polymer composition, molecular weight etc.) and physical properties (size, shape, surface charge) of the particle may be responsible for the variations in the intensity and duration of the inflammatory and wound healing processes [2].

Important in vivo characteristics of PLGA nanoand microparticles include their biodistribution, pharmacokinetics/dynamics and cellular uptake. For instance, one reason that nanoscaled (as opposed to microscaled) particles have been found to be of interest in drug delivery is that they can be transported (passively or actively) to tissues/cells distant from the site of injection. This makes it possible to design drug carrier systems that can pass biological barriers and seek target tissues where the drug can perform more efficiently.

We note that a recent expert review on clinical applications of PLGA based nanotechnology stated that a widespread clinical use of PLGA nanoparticles in clinical trails should be preceded by a thorough evaluation of their pharmacokinetics, biodistribution and immunotoxicity [50].

\section{PLGA Particles in Salmon Vaccines}

When we shift from mammals (in particular nonhuman primates and rodents) to fish, the lack of studies on effects of PLGA particles is much more obvious. Indeed, we have not encountered studies dedicated to the examination of these issues regarding use in fish. This is not unexpected since the use of PLGA particles in vaccine delivery in fish is a rather new research area, only addressed in a few publications $[10,45,61,72,73]$. These studies involve use of different research animals and vaccine concepts as summarized in Table 1. First, the five studies comprise four different species. Second, the three most recent studies aimed at developing vaccines against diseases affecting Japanese flounder (Paralichthys olivaceus) and Indian major carp (Labeo rohita)-species that are very different from salmonids in terms of physiology and habitat (e.g. temperature

Table 1 A summary of selected characteristics from previously published studies on PLGA vaccines on fish. Note that these studies were in the field of immunology

\begin{tabular}{|c|c|c|c|c|c|c|}
\hline Study & Species & Particle size & $\begin{array}{l}\text { Administration } \\
\text { site }\end{array}$ & Polymer & Antigen & $\begin{array}{l}\text { Negative side } \\
\text { effects }\end{array}$ \\
\hline [61] & $\begin{array}{l}\text { Atlantic salmon } \\
\text { (Salmo salar })\end{array}$ & $\begin{array}{l}\sim 5 \mu \mathrm{m}(2- \\
10 \mu \mathrm{m})\end{array}$ & Oral delvivery & PLGA 85:15 & $\begin{array}{l}\text { Human gamma } \\
\text { globulin (HGG) }\end{array}$ & None mentioned \\
\hline [45] & $\begin{array}{l}\text { Rainbow trout } \\
\text { (Oncorhynchus mykiss) }\end{array}$ & $\sim 1 \mu \mathrm{m}$ & Oral delivery & PLG & $\mathrm{HGG}$ & None mentioned \\
\hline [73] & $\begin{array}{l}\text { Japanese flounder } \\
\text { (Paralichthys olivaceus) }\end{array}$ & $<10 \mu \mathrm{m}$ & Oral delivery & PLGA 75:25 & pDNA & $\begin{array}{l}\text { No apparent } \\
\text { anaphylaxis }\end{array}$ \\
\hline [72] & $\begin{array}{l}\text { Japanese flounder } \\
\text { (Paralichthys olivaceus) }\end{array}$ & $<500 \mathrm{~nm}$ & Oral delivery & PLGA $75: 25$ & pDNA & None mentioned \\
\hline$[10]$ & $\begin{array}{l}\text { Indian major carp } \\
\text { (Labeo rohita) }\end{array}$ & $\sim 1 \mu \mathrm{m}$ & $\begin{array}{l}\text { Intra-peritoneal } \\
\text { injection }\end{array}$ & PLGA 50:50 & $\begin{array}{l}\text { Aeromonas hydrophila } \\
\text { (bacterial antigens) }\end{array}$ & None observed \\
\hline
\end{tabular}


and behaviour). Finally, the studies involved use of different drugs (antigen sources), polymer composition and particle sizes.

None of these studies report negative side effects. However, as registration of adverse side effects did not appear to be a major focus in these studies, no conclusions can be drawn in this respect, except that there seems to be a lack of targeted research on adverse effects.

One of the authors (B. N. Fredriksen) participates in an ongoing salmon PLGA vaccine project, in which several sub-experiments have been performed, including one on Atlantic cod (Gadus morhua). In these experiments, model- and pathogen derived antigens were encapsulated. Like the studies listed in Table 1, these experiments were designed to answer questions in immunology, not to address side effects of vaccination. Although the experimental setup did not involve systematic registration of side effects, some trends were observed. In salmon, one antigen-polymer combination resulted in quite severe side effects. However, when the same polymer was used to prepare particles for similar experiments using a different antigen (also in salmon) it did not result in any observable side effects. In cod, using a different polymer and twice the particle dose (due to low antigen loading in the particles), severe side-effects like exophthalmia (bulging eyes) and pigmentation were observed in the nanoparticle injected group. Such side effects were not seen in the oil-adjuvanted and non-injected groups. Observations like these may indicate that the combination of polymer and antigen is of importance for the differences in reactogenicity and immunogenicity between the formulations. Such antigenformulation related side effects have also been observed for oil-adjuvanted vaccines [55].

\section{PLGA Particles in the Aquatic System}

Salmon farms are semi-open systems interconnected with a surrounding aquatic environment. Although efforts have been invested to minimize salmon escapes, this remains a persistent problem. In combination with the biomass and numbers of vaccinated animals, the semi-open character of salmon farms presents us with a context in which the potential environmental implications of vaccine use are particularly important to evaluate.
Since PLGA particles will be subjected to hydrolysis in an aquatic medium they will be degraded over time if released into the environment from vaccine spills or decomposing tissues. However, degradation rates of the particles in the context of salmon farming have not been described. Since salmon is farmed at relatively low temperatures (generally between 5 and $15^{\circ} \mathrm{C}$ ) in Norway, we may expect slow degradation rates compared to experiments conducted in vitro at $37^{\circ} \mathrm{C}$. A highly important issue concerns the extent to which the nanoparticles can aggregate in the environment [66]. Aggregation may influence degradation rates of particles and their potential to affect organisms in the environment. It appears that little or no information is available about this aspect of PLGA nanoparticles in a marine context.

Accordingly, there is a need to initiate experiments investigating the stability of PLGA particles in aquatic systems, their uptake in aquatic organisms, including marine fish and mammals. While PLGA in itself seems to have a low potential for being toxic, we should not rule out the possibility that more complex structures of the polymer and combination with other compounds could give rise to undesirable properties. Since one of the major advantages of PLGA particles is that they are versatile carriers suitable for delivery of a wide range of therapeutics, it may be speculated that they could act as "Trojan horses" for different problematic substances in the environment. Due to their ability to attach hydrophobic or hydrophilic compounds and their ability to cross biological membranes, it is not entirely implausible that such particles could serve as carriers in unexpected and undesirable ways.

\section{Occupational Health and Human Consumers}

Although we know something about PLGA in mammals, this does not provide us with primary information about how humans may react to PLGA nanoparticle based fish vaccines. Such information, however, would be relevant for evaluating safety concerns of vaccine researchers, producers, vaccinators and salmon consumers.

The particles, which come in the form of a (freezedried) powder, are easily transported in air (B.N. Fredriksen, personal observation). In the literature we did not encounter studies on health impacts by inhalation of PLGA particles. We note here, however, that particles 
made of PLGA are biodegradable and are considered to be generally biocompatible. Further, rather low rates of PLGA uptake in human intestinal and bronchial cells have been reported [12]. Yet we consider it important to perform targeted research to identify adverse effects by inhalation, and that precaution is taken through ordinary means such as using face masks and fume hoods in research and production settings.

After production, the next step will be vaccination of fish. Here, the safety of workers needs attention. Self injections of fish vaccines by fish vaccinators, have been found to cause mild to more serious immunological reactions in humans [48, 64]. Although vaccination of fish is generally carried out by experienced professionals self-injections are not uncommon. In a range of interviews, 29 professional vaccinators reported 'one to more than 50 jabs or self injections' ([48]: 384). The significance of self injection is reflected in that a Norwegian fish vaccination handbook dedicates this concern a complete chapter [3]. Further, if a PLGA particle based salmon vaccine is to be marketed, it may be appropriate to monitor vaccinators for unexpected inflammatory and immunotoxic effects.

As farmed salmon is supposed to end on the dinner table, it is necessary to investigate whether the salmon filet or product contains vaccine residues. Although one can assume that the PLGA has been biodegraded in the time span between vaccination and slaughtering, this assumption needs to be followed up by experiments. As we address below, however, examinations and documentation of such issues form part of the regulatory requirements for vaccines used in animals for human food [28].

\section{Regulatory Aspects}

In the European Economic Area (EEA), advanced regulatory regimes have been developed to ensure the safety and efficacy of veterinary vaccines [28], including vaccines for fish [1]. However, nanomaterials have not previously been encountered in the regulatory context of fish vaccines, and it therefore remains to be seen how challenges raised by nanomedicines will be responded to here. ${ }^{1}$

\footnotetext{
${ }^{1}$ This is in contrast to, for instance, the European Community's framework for regulating chemicals, for which questions about how to regulate nanomaterials receives considerable attention (see e.g. [14])
}

For a new veterinary medicine to acquire a marketing authorization valid for the EEA, a range of conditions must be fulfilled. The producer of a veterinary medicine has the responsibility for providing documentation of (among other things) the medicine's therapeutic effect on the target organism and of the risks of adverse effects for animals, humans and the environment, respectively. In addition, a withdrawal period for animals intended for human consumption is determined in respect to established Maximum Residue Limits for pharmacologically active substances. ${ }^{2}$

The process of obtaining a market authorization for a new fish vaccine is a rather demanding, time consuming and costly affair, of which we cannot provide an adequate review here $[1,47] .^{3}$ Because Norway is a major player in salmon aquaculture and fish vaccine research in Europe and worldwide, it is relevant to consider a possible source of regulatory uncertainty within the Norwegian fish medicine regulations. In general, Norwegian regulations for veterinary medicines are shared with the EEA. As concerns fish medicines, the National Medicines Agency may, when this is applied for by individual veterinarians, allow the use of products before they have been granted a Norwegian marketing authorization [58]. Further, in the case of 'serious epidemic diseases' for which 'there exists no suitable medicine'([34]: §2-7), the Agency, may even allow the use of fish medicines that have not been approved in any EEA country. In critical situations, hence, there is a formal procedure in Norway allowing medicines to be taken into use before they have been fully risk assessed-a practise that historically has not been unexceptional. The rationale of this exemption is of course that the risk associated with developing epidemics justifies taking more risks with regard to side effects of vaccines.

Two factors count in favour of the existing framework regulating and overseeing the use of vaccines for fish, including prospective nanomedicines. First, it requires substantial and direct testing of efficacy and side effects of any new vaccine. Second,

\footnotetext{
${ }^{2}$ Apparently, however, no Maximum Residue Limit has been determined for PLGA in foodstuff so far [19].

${ }^{3}$ See: http://www.ema.europa.eu/ema/index.jsp?curl=pages/ regulation/landing/veterinary_medicines_regulatory.jsp\&murl=menus/regulations/regulations.jsp\&mid $=$ WC0b01 ac058001 ff8a (last visited 12.12.2010)
} 
it includes extensive vigilance regarding new vaccines. The question we raise is whether the particular features of nanomedicines will be taken into account in this framework in sufficiently robust way. Will established risk assessment and monitoring procedures be adequate for considering long-term side effects in target animals, the environment, and human consumers when it comes to nanomedicines?

\section{Anticipating Nanovaccines for Salmon: Assessment and Recommendations}

We have examined expected benefits and potential harms of the use of PLGA nanoparticles in vaccines for farmed salmon. Given the complexity of the case, we do not consider this work a complete assessment. A more comprehensive assessment would in particular require a closer examination of regulatory aspects. Here we will go over the main points from our examination, which in turn will provide a basis for our suggestions for how governance of such fish vaccines in practice may be prepared for.

We have characterized the rationale and prospective benefits of using small PLGA particles in salmon vaccines. Obvious benefits of improved salmon vaccines include improved animal welfare and economics of salmon farming. In addition, improved vaccines may reduce the spread of infectious diseases to wild salmon.

The main emphasis of this work has been on the mapping of potential harmful effects, which we structured in terms of their location (Fig. 1). For each location addressed, we presented available knowledge about possible negative side effects, and we identified knowledge gaps. We began with a focus on the PLGA material and its various therapeutic uses in mammals (including humans), of which there is an extensive scientific literature. We then considered the more specific application of PLGA in fish vaccines, of which few studies are currently published. From the target area of the injected vaccines we shifted outwards (in Fig. 1) to a consideration of potential side effects for the fish, the aquatic environment, professionals working with producing or administering the vaccine, and humans consuming vaccinated fish and regulation issues. Moving out from the vaccines target area, the available scientific information increasingly got sparse and less specific, imply- ing that, in the terminology of Walker et al. [74], the level of uncertainty increased towards ignorance. A similar pattern has been identified for other novel types of fish vaccines [27]. As a corollary, our considerations became increasingly suggestive as we moved away from the vaccine's target area.

The addressed PLGA vaccine concept comes with two particular sources of uncertainty, which relate to the use of particles in the nano range and to context sensitivity regarding the exact PLGA particle based vaccine formulation being used. We recognized the importance of context sensitivity in different ways. Importantly, the safety of the carrier depends on what it carries and vice versa (interactive effects). For instance, we noted this in relation to the observations from ongoing experiments with PLGA particle based vaccines for salmon and cod. Further, while information about the use of PLGA particles in delivery of therapeutics in mammals is abundant, the context of fish vaccines raises the question of to what extent knowledge about one group of animal species (e.g. mammals) is relevant for another (e.g. fish). This relevance may even be questioned regarding more closely related species.

The lack of context specific information relevant for the evaluation of environmental and health aspects of a PLGA based salmon vaccine owes much to the fact that such a vaccine has not yet been suggested as a product; it remains in an explorative research phase as we write, and much of the information presently available is indirect insofar it stems from research focusing on vaccine efficiency, not its safety aspects. If such a vaccine concept would be perceived to be sufficiently promising (i.e. high level of protection and low level of negative side effects), its efficacy, product quality and safety would need to be documented in accordance with existing regulations. While this documentation process would generate context specific information, a pivotal issue is whether 'nano aspects' would be sufficiently taken into account. This issue is addressed in our recommendations, to which we now turn.

First, we recommend the prioritisation of research, which is not only targeted to testing and improving the efficacy of vaccines, but which contributes to a thorough evaluation of effects in terms of pharmacokinetics, biodistribution and immunotoxicity of small PLGA particles following vaccine administration. Further, there is a need of research into methods to 
measure such effects, not only in salmon, but also in humans, animals and the environment. This includes research investigating the stability of PLGA particles in aquatic systems, and their uptake in aquatic organisms. For instance, tests of intestinal contents of predators and of microbial flora in the immediate environment of vaccinated subjects may provide indications of the environmental release and persistence of PLGA particles.

Second, while PLGA in itself seems to have a low potential for being toxic, we noted that it could have unanticipated outcomes such as PLGA particles serving as 'Trojan horses' for problematic substances in the environment. Accordingly, the potential role of the PLGA particles to act as carriers of toxic compounds should be examined, as should their potential for having harmful synergistic effects with other particles and chemicals.

Third, as we moved outwards from the vaccine's target areas in Fig. 1, knowledge of effects became scarce, and we moved into ignorance. In situations characterized by ignorance, it is important to initiate research into methods for detection and monitoring of unanticipated effects. While there exists an internationally coordinated system for reporting 'suspected adverse events' for veterinary medicinal products authorised in the EEA, ${ }^{4}$ methods should preferably be developed for detecting persistence and biodistribution of small (e.g. sub micron) particles. As suggested by Wickson et al. [75] monitoring of unanticipated effects is not only a task for scientists, but would here naturally involve manufactures of the vaccines, vaccinators, veterinarians, and fish farmers.

Finally, we recommend that present scientific knowledge, and its limitations, should be exposed to some form of extended peer review [25] prior to that nanoparticle based salmon vaccines are taken into use on a larger scale. The framework suggested by Walker et al. [74], perhaps as simplified and adapted here, may be useful for enabling a structured presentation of available scientific knowledge and uncertainties in relevant areas. Such a presentation could provide a background for an extended review process, which preferably should involve participants of complementing scientific disciplines, regulators, organized interest groups and members of a broader public (e.g.

\footnotetext{
${ }^{4}$ http://eudravigilance.emea.europa.eu/veterinary/(last visited 14.12.2010)
}

consumers). Questions that may be relevant to address here include: Is the size reduction from PLGA microparticles to PLGA nanoparticles critical with regard to risks in this new context? May fish respond in different ways than humans or other mammals, about which we have previous information regarding the biocompatibility of PLGA? Does the large-scale use of PLGA in semi-open systems such as salmon aquaculture facilities represent different, e.g. environmental, risks than its previous uses?

\section{Anticipatory Governance of Nanotechnologies- The Challenge of Nano-Diversity}

There is a strong motivation to anticipate unwanted effects of technologies as early as possible. In general, this motivation stems from previous experiences with novel technologies that turned out to have unexpected and harmful effects [31]. Technology researchers and developers have a particularly compelling incentive for seeking to anticipate harmful effects, which derives from the fact that product development (i.e. testing and documenting efficacy, quality and safety) is lengthy and costly. There is simply no point in testing a concept (e.g. a vaccine) before one is reasonably sure that it will be good and safe. If modified, however slightly, the concept would require a new round of tests and documentation. This incentive can be utilized in the facilitation of anticipatory governance approaches, whether through interdisciplinary exercises or through other approaches that we return to below.

A well known challenge for any evaluation of a technology at an early stage is that little knowledge will be available for supporting the evaluation [15]. In the present case, it proved difficult to evaluate potential harmful effects of a vaccine concept, which is not yet stabilized in the sense that different vaccine/particle configurations are still being tested. In general, little context specific information will be available (i.e. published) prior to that a technology has been tested and documented regarding its efficacy and safety. In this situation we believe that researchers exploring the technological concept in question will represent the most valuable source of context specific knowledge about safety, side effects and knowledge gaps.

We believe that efforts to anticipate harmful effects of nanotechnologies will meet a further challenge. 
Because of the diversity of nanotechnologies, it will be extremely difficult for any singly agency to maintain an overview of nanotechnology research as such. In particular, it is difficult to overview the diverse array of individual research projects that are carried out by research groups located in environments that (such as it is the case for the discussed fish vaccine project) are not defined, organized or identified as nanotechnology research environments as such (see Nielsen et al. [57], this issue). Low profile nanotechnology projects of different kinds may not receive much attention from research environments dedicated to the evaluation of the toxicology and ecotoxicology of nanomaterials. We suggest that technology researchers also represent an invaluable resource for addressing this challenge.

The approach taken here represents one way to utilize tacit and explicit knowledge of technology researchers in order to facilitate anticipatory governance in a given context. We found that the interdisciplinary aspect of our approach allowed for useful synergies when characterizing benefits, risks and uncertainties as well as issues in need of further research at an early stage of technology development. However, it appears unlikely that there will be time and resources available for conducting exercises of this kind in relation to all nanotechnology projects. Accordingly we end this article by endorsing the further development of voluntary measures and codes of conducts for good technology research practises, which we see as complementary ways to mobilize the knowledge of technology researchers in anticipatory governance efforts.

Approaches that seek to promote a broad sense of responsibility [38] among technology researchers may help to anticipate unwanted side effects. For instance, voluntary instruments such as the EU's "Code of Conduct for Responsible Nanosciences and Nanotechnologies Research" [13] may help in rendering researchers more sensitive to potential environmental health and safety implications of their research. In Norway, a more general set of "Guidelines for Research Ethics in Science and Technology" [56] has been suggested, which among other things seeks to make precautionary thinking relevant for individual researchers in upstream settings [71].

Soft law approaches, however, are not unproblematic. We observe that there apparently, at least in a Norwegian nanotechnology research setting, is little awareness of both the EUs Code of Conduct and the Norwegian guidelines for research ethics. ${ }^{5}$ Further, we note that these guidelines in themselves are problematic. In particular, the present Norwegian guideline confers the individual researcher with quite demanding obligations, and it appears unclear how $\mathrm{s} /$ he may fulfil a responsibility in the way it is outlined. There seems to be challenges with, as well as a scope for improvement of, approaches that involve technology researchers in anticipatory governance efforts.

Acknowledgements This work has been economically supported by the Research Council of Norway (Grant 182046 - the 'Nanotrust' project). We thank two anonymous reviewers for encouraging as well as critical and constructive reviews. We are particularly indebted to researchers working on a PLGA nanoparticle based salmon vaccine project in Norway.

Open Access This article is distributed under the terms of the Creative Commons Attribution Noncommercial License which permits any noncommercial use, distribution, and reproduction in any medium, provided the original author(s) and source are credited.

\section{References}

1. Alderman DJ (2009) Control of the use of veterinary drugs and vaccines in aquaculture in the European union. Options Méditerr 86:13-28

2. Anderson JM, Shive MS (1997) Biodegradation and biocompatibility of PLA and PLGA microspheres. Adv Drug Deliv Rev 28:5-24

3. Anon (1992) Vaksinehåndboken. NorBio AS, Bergen

4. Athanasiou KA, Niederauer GG, Agrawal CM (1996) Sterilization, toxicity, biocompatibility and clinical applications of polylactic acid/polyglycolic acid copolymers. Biomaterials 17:93-102

5. Avgoustakis K, Beletsi A, Panagi Z, Klepetsanis P, Livaniou E, Evangelatos G, Ithakissios DS (2003) Effect of copolymer composition on the physicochemical characteristics, in vitro stability, and biodistribution of PLGAmPEG nanoparticles. Int J Pharm 259:115-127

6. Banchereau J, Steinman RM (1998) Dendritic cells and the

\footnotetext{
$\overline{5}$ This statement is based on a range of interviews with nanotechnology researchers and people knowledgeable about, and professionally interested in, nanotechnology issues. The (semi-structured) interviews were conducted in Norway in 2009. Of the interviewed people, less than half had heard about the EU's code of conduct and/or the NENT guideline. Few had read the documents, in particular if we except people that would be expected to know about these documents because of their academic speciality (e.g. experts in ethics of science and technology). This impression is consistent with Kjølberg [38].
} 
control of immunity. Nature 392:245-252

7. Barben D, Fisher E, Selin C, Guston DH (2008) Anticipatory governance of nanotechnology: foresight, engagement, and integration. In: Hackett EJ, Amsterdamska O, Lynch M, Wajcman $\mathrm{J}$ (eds) The handbook of science and technology studies, 3rd edn. MIT Press, Cambridge

8. Baun A, Hansen SF (2008) Environmental challenges for nanomedicine. Nanomedicine 3:605-608

9. Beck LR, Pope VZ, Flowers CE, Cowsar DR, Tice TR, Lewis DU, Dunn RL, Moore AB, Gilley RM (1983) Poly (DL- Lactide-co-glycolide)/norethisterone microcapsules: an injectable biodegradable contraceptive. Biol Reprod 28:186-195

10. Behera T, Nanda PK, Mohanty C, Mohapatra D, Swaina P, Das BK, Routray P, Mishra BK, Sahoo SK (2010) Parenteral immunization of fish Labeo rohita with Poly D, L-lactide-co-glycolic acid (PLGA) encapsulated antigen microparticles promotes innate and adaptive immune responses. Fish Shellfish Immunol 28:320-325

11. Berg A, Bergh Ø, Fjelldal PG, Hansen T, Juell JE, Nerland A (2006) Animal welfare and fish vaccination-effects and side-effects (in Norwegian). Institute of Marine Research, Bergen

12. Cartiera MS, Johnson KM, Rajendran V, Caplan MJ, Saltzman WM (2009) The uptake and intracellular fate of PLGA nanoparticles in epithelial cells. Biomaterials 30:2790-2798

13. CEC (2008) Code of conduct for responsible nanosciences and nanotechnologies research. Commission of the European Communities, Brussels

14. CEC (2008) Communication from the commission to the European parliament, the council and the European economic and socia committee: regulatory aspects of nanotechnology. Commission of the European Communities, Brussels

15. Collingridge D (1980) The Social control of technology. Frances Pinter, London

16. Diwan M, Elamanchili P, Lane H, Gainer A, Samuel J (2003) Biodegradable nanoparticle mediated antigen delivery to human cord blood derived dendritic cells for induction of primary $\mathrm{T}$ cell responses. $\mathrm{J}$ Drug Target 11:495-507

17. Dobrovolskaia MA, McNeil SE (2007) Immunological properties of engineered nanomaterials. Nat Nanotechnol 2:469-478

18. Draper SJ, Heeney JL (2010) Viruses as vaccine vectors for infectious diseases and cancer. Nat Reviews Microbiol $8: 62-73$

19. EC. (2010) Commission Regulation (EU) No 37/2010 of 22 December 2009 on pharmacologically active substances and their classification regarding maximum residue limits in foodstuffs of animal origin. Official Journal of the European Union, L15

20. Eggset G, Mikkelsen H, Killie JE (1997) Immunocompetence and duration of immunity against Vibrio salmonicida and Aeromonas salmonicida after vaccination of Atlantic salmon (Salmo salar L.) at low and high temperatures. Fish Shellfish Immunol 7:247-260

21. Elamanchili P, Lutsiak CME, Hamdy S, Diwan M, Samuel J (2007) "Pathogen-Mimicking" nanoparticles for vaccine delivery to dendritic cells. J Immunother 30:378-395
22. Ellis AE (1996) Immunization with bacterial antigens: furunculosis. Dev Biol Stand 90:107-116

23. Esmaeili F, Ghahremani MH, Esmaeili B, Khoshayand MR, Atyabi F, Dinarvand R (2008) PLGA nanoparticles of different surface properties: preparation and evaluation of their body distribution. Int J Pharm 349:249-255

24. Faurez F, Dory D, Moigne VL, Gravier R, Jestin A (2010) Biosafety of DNA vaccines: new generation of DNA vectors and current knowledge on the fate of plasmids after injection. Vaccine 28:3888-3895

25. Funtowicz S, Ravetz J (1993) Science for the post-normal age. Futures 25:735-755

26. Gilding DK, Reed AM (1979) Biodegradable polymers for use in surgery polyglycolic/poly(actic acid) homo- and copolymers. Polymer 20:1459-1464

27. Gillund F, Kjølberg KA, Krayer MPK, Myhr AI (2008) Do uncertainty analyses reveal uncertainties? Using the introduction of DNA vaccines to aquaculture as a case. Sci Total Environ 407:185-196

28. Grein K, Papadopoulos O, Tollis M (2007) Safe use of vaccines and vaccine compliance with food safety requirements. Rev Sci Tech Off Int Epizoot 26:339-350

29. Grieger KD, Hansen S, Baun A (2009) The known unknowns of nanomaterials: describing and characterising uncertainty within environmental, health and safety risks. Nanotoxicology 3:222-233

30. Gudding R, Lillehaug A, Evensen Ø (1999) Recent developments in fish vaccinology. Vet Immunol Immunopathol 15:203-212

31. Harremoes P, Gee D, MacGarvin M, Stirling A, Keys J, Wynne B, Vaz SG (eds) (2002) The precautionary principle in the 20th century-late lessons from early warnings. EARTHSCAN, London

32. Hassan MK, Mauritz KA, Storey RF, Wiggins JS (2006) Hydrolytic degradation of poly(DL-lactide) as a function of end group: carboxylic acid vs. Hydroxyl Polym 47:19601969

33. Håstein T, Gudding R, Evensen Ø (2005) Bacterial vaccines for fish - an update of the current situation worldwide. In: Midtlyng PJ (ed) Progress in fish vaccinology. Karger, Basel, pp 55-74

34. HOD. (2010) Forskrift om legemidler (legemiddelforskriften), HOD (Helse- og omsorgsdepartementet: the Health Department), FOR-2009-12-18-1839. Retrieved March 2011 from http://www.lovdata.no/cgi-wift/wiftldrens?/app/ gratis/www/docroot/ltavd1/filer/ sf-20091218-1839.html

35. Hubbell JA, Thomas SN, Swartz MA (2009) Materials engineering for immunomodulation. Nature 462:449-460

36. Jong WHD, Borm PJA (2008) Drug delivery and nanoparticles: applications and hazards. Int $\mathrm{J}$ Nanomedicine 3:133-149

37. Karinen R, Guston DH (2010) Toward anticipatory governance: the experience with nanotechnology. In: Kaiser M, et al. (ed) Governing future technologies. Springer Science

38. Kjølberg K (2010) The notion of responsible development in new approaches to governance of nanosciences and nanotechnologies. Dissertation, The University of Bergen

39. Koppang EO, Bjerkas I, Haugarvoll E, Chan EKL, Szabo NJ, Ono N, Akikusa B, Jirillo E, Poppe TT, Sveier H, Torud B, Satoh M (2008) Vaccination-induced systemic 
autoimmunity in farmed salmon. J Immunol 181:48074814

40. Kovacsovics-Bankowski M, Clark K, Benacerraf B, Rock K (1993) Efficient major histocompatibility complex I presentation of exogenous antigen upon phagocytosis by macrophages. Proc Natl Acad Sci 90:4942-4946

41. Krauss MPK, Casman EA, Small MJ (2004) Elicitation of expert judgement of uncertainty in the risk assessments of herbicide-tolerant oilseed crops. Risk Anal 24:1515-1527

42. Krauss MPK, Kaiser M, Almaas V, Sluijs J, Kloprogge P (2008) Diagnosing and prioritizing uncertainties according to their relevance for policy: the case of transgene silencing. Sci Total Environ 390:23-34

43. Kuzma J (2010) Nanotechnology in animal productionupstream assessment of applications. Lifestock Sci 130:14-24

44. Kuzma J, Romanchek J, Kokotovich A (2008) Upstream oversight assessment for agrifood nanotechnology: a case studies approach. Risk Anal 4:1081-1098

45. Lavelle EC, Jenkins PG, Harris JE (1997) Oral immunization of rainbow trout with antigen microencapsulated in poly(DL-lactide-co-glycolide) microparticles. Vaccine 15:1070-1076

46. Lecaroz C, Gamazo C, Renedo MJ, Blanco-Prieto MJ (2006) Biodegradable micro- and nanoparticles as longterm delivery vehicles for gentamicin. J Microencapsul 23:782-792

47. Lee A (1997) European regulations relevant to the marketing and use of fish vaccines. Dev Biol Stand 90:341-346

48. Leira HL, Baalsrud KJ (1997) Operator safety during injection vaccination of fish. In: Gudding R, Lillehaug A, Midtlyng PJ, Brown F (eds) Fish vaccinology. Karger, Basel

49. Li J, Barreda DR, Zhang YA, Boshra H, Gelman AE, Lapatra S, Tort L, Sunyer JO (2006) B lymphocytes from early vertebrates have potent phagocytic and microbicidal abilities. Nat Immunol 7:1116-1124

50. Lü J, Wang X, Marin-Muller C, Wang H, Lin PH, Yao Q, Chen C (2009) Current advances in research and clinical applications of PLGA-based nanotechnology. Expert Rev Mol Diagn 9:325-341

51. Lugo-Villarino G, Balla KM, Stachura DL, Bañuelos K, Werneck MBF, Traver D (2010) Identification of dendritic antigen-presenting cells in the zebrafish. Proc Natl Acad Sci 107:18079-18084

52. Macnaghten P, Kearnes MB, Wynne B (2005) Nanotechnology, governance, and public deliberation: what role for the social sciences? Sci Commun 27:268-291

53. McKee AS, MacLeod MKL, Kappler JW, Marrack $P$ (2010) Immune mechanisms of protection: can adjuvants rise to the challenge? BMC Biol 8:1-10

54. Midtlyng PJ, Reitan LJ, Lillehaug A, Ramstad A (1996) Protection, immune responses and side effects in Atlantic salmon (Salmo salar L.) vaccinated against furunculosis by different procedures. Fish Shellfish Immunol 6:599-613

55. Mutoloki S, Alexandersen S, Evensen Ø (2004) Sequential study of antigen persistence and concomitant inflammatory reactions relative to side-effects and growth of Atlantic salmon (Salmo salar L.) following intraperitoneal injection with oil-adjuvanted vaccines. Fish Shellfish Immunol 16:633-644
56. NENT. (2007) Guidelines for research ethics in science and technology, in the national committee for research ethics in science and Technology (NENT: http://www.etikkom.no/ English/Publications/NENTguidelines)

57. Nielsen KN, Åm TG, Nydal R (2011) Centre and periphery of nano-a Norwegian context. Nanoethics. doi:10.1007/ s11569-011-0110-6

58. NMA. (2010) Medicinal products used in fish farming in Norway. Norwegian Medicines Agency (NMA)

59. NVI (2009) Fiskehelserapporten. [The fish health report]. National Veterinary Institute, Oslo

60. Odelstinget (2009) Vedtak til lov om dyrevelferd. Besl. O. nr. 77. Retrieved March 2011 from http://www.stortinget. no/no/Saker-og-publikasjoner/Vedtak/Beslutninger/ Odelstinget/2008-2009/beso-200809-077/1/

61. O'Donnel GB, Reilly P, Davidson GA, Ellis AE (1996) The uptake of human gamma globulin incorporated into poly (D,L-lactide-co-glycolide) microparticles following oral intubation in Atlantic salmon, Salmo salar L. Fish Shellfish Immunol 6:507-520

62. Ogawa Y, Yamamoto M, Okada H, Yashiki T, Shimamoto $\mathrm{T}$ (1988) A new technique to efficiently entrap leuprolide acetate into microcapsules of polylactic acid or copoly (lactic/glycolic) acid. Chem Pharm Bull 36(3):1095-1103

63. Olesen I, Myhr AI, Rosendal GK (2010) Sustainable aquaculture: are we getting there? Ethical perspectives on salmon farming. J Agric Environ Ethics, Epub ahead of print

64. O'Neill AC, Ismael TS, McCann J, Regan PJ (2005) Fish vaccine injection injuries of the hand. $\mathrm{Br} \mathrm{J}$ Plast Surg 58:547-549

65. Panyam J, Dali MM, Sahoo SK, Ma W, Chakravarthi SS, Amidon GL, Levy RJ, Labhasetwara V (2003) Polymer degradation and in vitro release of a model protein from poly(D, L-lactide-co-glycolide) nano- and microparticles. J Control Release 92:173-187

66. Petosa AR, Jaisi DP, Quevedo IR, Melimelech M, Tufenkji N (2010) Aggregation and deposition of engineered nanomaterials in aquatic environments: role of physicochemical interactions. Environ Sci Technol 44:6532-6549

67. Rakoto-Andrianarivelo M, Gumede N, Jegouic S, Balanant J, Andriamamonjy SN, Rabemanantsoa S, Birmingham M, Randriamanalina B, Nkolomoni L, Venter M, Schoub BD, Delpeyroux F, Reynes J-M (2008) Reemergence of recombinant vaccine-derived poliovirus outbreak in Madagascar. J Infect Dis 197:1427-1435

68. Schliehe C, Schliehe C, Thiry M, Tromsdorf UI, Hentschel J, Weller H, Groettrup M (2011) Microencapsulation of inorganic nanocrystals into PLGA microsphere vaccines enables their intracellular localization in dendritic cells by electron and fluorescence microscopy. J Control Release, Epub ahead of print

69. Schlosser E, Mueller M, Fischer S, Basta S, Busch DH, Gander B, Groettrup M (2008) TLR ligands and antigen need to be coencapsulated into the same biodegradable microsphere for the generation of potent cytotoxic $\mathrm{T}$ lymphocyte responses. Vaccine 26:1626-1637

70. Sommerset I, Krossøy B, Frost P (2005) Vaccines for fish in aquaculture. Vaccines 4:89-101

71. Throne-Holst H, Stø E (2008) Who should be precautionary? Governance of nanotechnology in the risk society. Technol Anal Strateg Manag 20:99-112 
72. Tian J, Ya J (2010) Poly(lactic-co-glycolic acid) nanoparticles as candidate DNA vaccine carrier for oral immunization of Japanese flounder (Paralichthys olivaceus) against lymphocystis disease virus. Fish Shellfish Immunol, in press

73. Tian J, Sun X, Chen X, Yu J, Qu L, Wang L (2008) The formulation and immunisation of oral poly(DL-lactide-coglycolide)microcapsules containing a plasmid vaccine against lymphocystis disease virus in Japanese flounder (Paralichthys olivaceus). Int Immunopharmacol 8:900-908

74. Walker WE, Harremöes P, Rotmans J, Sluijs JP, Asselt MBA, Janssen P, Krayer KMP (2003) Defining uncertainty; a conceptual basis for uncertainty management in model based decision support. Integr Assess 4:5-17

75. Wickson F, Gillund F, Myhr AI (2010) Treating nanoparticles with precaution: recognising qualitative uncertainty in scien- tific risk assessment. In: Kjølberg K, Wickson F (eds) Nano meets macro: social perspectives on nanoscale sciences and technologies. Pan Stanford Publishing, Singapore

76. Yang Y, Chung T, Ng NP (2001) Morphology, drug distribution, and in vitro release profiles of biodegradable polymeric microspheres containing protein fabricated by double-emulsion solvent extraction/evaporation method. Biomaterials 22:231-241

77. Yewdell JW, Haeryfar SMM (2005) Understanding presentation of viral antigens to CD8 $+\mathrm{T}$ cells in vivo: the key to a rational vaccine design. Annu Rev Immunol 23:651-682

78. Yushu H, Venkatraman S (2006) The effect of process variables on the morphology and release characteristics of protein-loaded PLGA particles. J Appl Polym Sci 101:3053-3061 